Author has nothing to disclose with regard to commercial support.

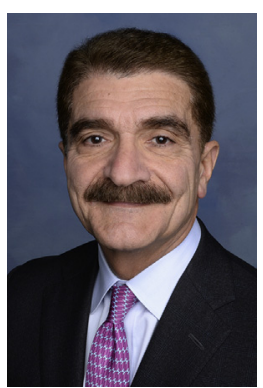

\section{A VICTORY FOR ALL HALSTEDIANS: EVIDENCE SUPPORTING CARDIAC SURGICAL RESIDENTS TRAINING To the Editor:}

We appreciated Dr Mokadam's editorial $^{1}$ discussing resident versus attending surgeon graft patency and clinical outcomes from the Randomized On/Off Bypass (ROOBY) trial published in the December 2015 issue of the Journal. ${ }^{2}$ As Dr Mokadam noted, these ROOBY substudy results are very encouraging for resident education, support current Halstedian principles of residency training, and have positive implications for patients and hospitals in academic settings.

However, Dr Mokadam raised several issues that deserve a response or further clarification. For example, we believe he mischaracterized the study as "...a retrospective subgroup analysis of a prospective randomized trial." ${ }^{1}$ More accurately, this was a prospective cohort substudy ${ }^{3}$ that was preplanned and conducted within the ROOBY trial. Prospective data gathering minimizes risk of biases associated with retrospective studies. ${ }^{4}$ Moreover, the level of precision of prospectively collected intraoperative graftby-graft assessments would not be possible in a retrospective analysis using existing administrative databases or by reviewing medical charts.

Dr Mokadam's question of whether the attending setting up the anastomosis may have moved the table under the resident has potential merit. However, his question raised of whether the resident completed $51 \%, 75 \%$, or $100 \%$ of the sutures for a distal anastomosis was an unusual one; in our ROOBY trial's experience, attendings generally permitted the resident to perform all of the sutures for each distal placed.

Dr Mokadam also questioned if ROOBY attending physicians performed the "worst" distals and left the "easier"

\footnotetext{
The Editor welcomes submissions for possible publication in the Letters to the Editor section that consist of commentary on an article published in the Journal or other relevant issues. Authors should: $\bullet$ Include no more than 500 words of text, three authors, and five references. • Type with double-spacing. • See http://jtcs.ctsnetjournals.org/ misc/ifora.shtml for detailed submission instructions. • Submit the letter electronically via jtcvs.editorialmanager.com. Letters commenting on an article published in the JTCVS will be considered if they are received within 6 weeks of the time the article was published. Authors of the article being commented on will be given an opportunity of offer a timely response ( 2 weeks) to the letter. Authors of letters will be notified that the letter has been received. Unpublished letters cannot be returned.
}

anastomoses for their residents. Admittedly, data on vessel quality and size are by nature "coarse" and subjective, but the ROOBY trial's qualitative metrics available were presented in Table 3. ${ }^{2}$ Target vessel sizes were documented to be similar or larger for grafts placed by attending surgeons compared with residents.

As stated best by Dr Mokadam, a future randomized controlled trial comparing resident with attending surgeon "would be impossible to conduct." Given that the attending faculty member's primary goal is always to ensure each patient's safety, equipoise may never exist to randomize the intraoperative care (eg, sewing in the distal coronary anastomosis) of any patient undergoing coronary artery bypass grafting to a senior faculty expert surgeon versus an inexperienced trainee. In surgical education, the successful completion of a case clearly documents that the trainee's roles and responsibilities were fulfilled and adequately supervised by his or her attending surgeon.

Toward the goal of supporting future cardiothoracic surgical educational scholarship, we remain resolute that this ROOBY substudy ${ }^{2}$ represents an important, positive step forward. As all ROOBY trial attending faculty and leadership team members remain educators first and foremost, the concept of training surgical residents and fellows will always be very close to our hearts.

G. Hossein Almassi, $M D^{a}$

A. Laurie W. Shroyer, PhD, $M S H A^{b}$

Faisal G. Bakaeen, $M D^{c}$

${ }^{a}$ Cardiothoracic Surgery

Medical College of Wisconsin and Veterans Affairs Medical

Center

Milwaukee, Wis

${ }^{b}$ Surgery

Northport VA Medical Center and Stony Brook School of

Medicine

Stony Brook, NY

${ }^{c}$ Cardiothoracic Surgery

Cleveland Clinic Foundation

Cleveland, Ohio

This Letter to the Editor was supported by the Cooperative Studies Program Coordinating Center in Perry Point, Maryland, and the respective Offices of Research and Development at the Zablocki VA Medical Center, Northport VA Medical Center, and VA Eastern Colorado Healthcare System.

\section{References}

1. Mokadam NA. A victory for the Halsteadians? J Thorac Cardiovasc Surg. 2015 150:1438-9.

2. Almassi GH, Carr BM, Bishawi M, Shroyer AL, Quin JA, Hattler B, et al; for the Veterans Affairs \#517 Randomized On/Off Bypass (ROOBY) Study Group. Resident versus attending surgeon graft patency and clinical outcomes in on- versus off-pump coronary artery bypass surgery. J Thorac Cardiovasc Surg. 2015;150: 1428-37.e1.

3. Cummings SR, Newman TB, Hulley SB. Designing Clinical Research. In Hulley SB, Cummings SR, Browner WS, Grady DG, Newman TB, eds. Designing 
Clinical Research. 3rd ed. Philadelphia, PA: Lippincott Williams \& Wilkins; 2007:97-108.

4. Pannucci CJ, Wilkins EG. Identifying and avoiding bias in research. Plast Reconstr Surg. 2010;126:619-25.

\section{http://dx.doi.org/10.1016/j.jtcvs.2015.12.038}

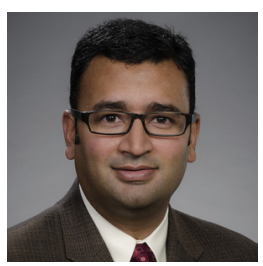

\section{THE EVIDENCE IS SUSPECT} Reply to the Editor:

I have read the letter to the Editor from Almassi and colleagues with great interest. ${ }^{1}$ They have attempted to provide additional clarity to their recently published article $^{2}$ and its accompanying editorial. ${ }^{3}$ There is no question that the authors of this study "remain educators first and foremost..." However, the shortcomings of this study, which is no reflection on the authors' commitment to education, are not ameliorated by their comments.

If this study is analyzed according to the Zwisch Model ${ }^{4}$ (supervision is characterized as "show and tell," "smart help," "dumb help," and "no help"), the role of the resident is unclear. The authors state that "attendings generally permitted the resident to perform all of the sutures for each distal placed." This scenario is certainly not "show and tell," but it does not discriminate among "smart," "dumb," and "no help." Similarly, the comment that "target vessel sizes were documented to be either similar or larger..." does not demonstrate the resident's role in choosing the target, assessing its suitability and quality, or even opening the vessel. The most surprising statement comes later: "In surgical education, the successful completion of a case clearly documents that the trainee's roles and responsibilities were fulfilled and adequately supervised by their attending surgeon." Certainly, completion of an operation is a mandate, with or without residents present; demonstration of surgical education, by any standard, is not met simply because a resident was in the operating room.

Ultimately, we are all invested in resident education, and the authors deserve credit for their attempt at measuring resident involvement. However, this study highlights the challenges inherent in documenting resident role in an operation; unfortunately, the evidence is not sufficient to support their conclusions.

Nahush A. Mokadam, MD Division of Cardiothoracic Surgery University of Washington Seattle, Wash

\section{References}

1. Almassi GH, Shroyer LW, Bakaeen FG. A victory for all Halsteadians: evidence supporting cardiac surgical residents training. J Thorac Cardiovasc Surg. 2016; $151: 1215$.
Author has nothing to disclose with regard to commercial support.

2. Almassi GH, Carr BM, Bishawi M, Shroyer AL, Quin JA, Hattler B, et al; Veterans Affairs \#517 Randomized On/Off Bypass (ROOBY) Study Group. Resident versus attending surgeon graft patency and clinical outcomes in on- versus off-pump coronary artery bypass surgery. J Thorac Cardiovasc Surg. 2015;150:1428-37.e1.

3. Mokadam NA. A victory for the Halsteadians? J Thorac Cardiovasc Surg. 2015; 150:1438-9.

4. DaRosa DA, Zwisschenberger JB, Meyerson SL, George BC, Teitelbaum EN, Soper NJ, et al. A theory-based model for teaching and assessing residents in the operating room. J Surg Educ. 2013;70:24-30.

http://dx.doi.org/10.1016/j.jtcvs.2016.01.013

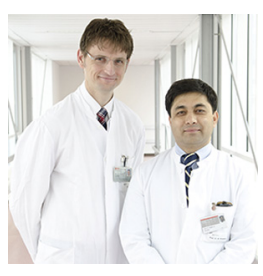

\section{FROZEN ELEPHANT TRUNK VERSUS SINGLE-STAGE OPEN REPAIR FOR EXTENSIVE THORACIC AORTIC DISEASE} Reply to the Editor:

We thank Kouchoukos for commenting on our recent article, "The Elephant Trunk Is Freezing: The Hannover Experience." 1 He pointed out that the alternative to both the conventional and frozen elephant trunk (FET) technique to treat complex aortic arch pathology is an extended open single-stage operation. ${ }^{2-4}$ Our group compliments Kouchoukos for his outstanding role in thoracic aortic surgery in general and specifically for his pioneering work with the single-stage approach.

As was pointed out by Kouchoukos, patients with acute aortic dissection have infrequently undergone extended one-stage open repair. A comparison between patients with chronic aortic dissection undergoing extended onestage repair and those alternatively undergoing a FET procedure was suggested. The complexity of the extended one-stage technique, however, as well as its invasiveness for the patient, seems to discourage the less experienced thoracic aortic surgeon, because only a few groups have actually adopted the concept as yet.

Our group of 51 patients with chronic aortic dissection who had undergone a FET procedure within the study period (August 2001-March 2013) comprised the complete learning curve of this procedure, from the first prefabricated FET graft $^{5}$ to the novel branched FET grafts first introduced in $2010 .^{6}$ Indications and surgical techniques have changed markedly with increasing experience and the use of branched grafts. ${ }^{7}$ We recently completed a risk analysis of our contemporary techniques (presented at the annual meeting of the European Association for Cardio-Thoracic Surgery in October 2015). It included 18 patients with chronic aortic dissection treated between April 2013 and April 2015 with complete aortic arch repair by means of the FET technique $(67 \%$ male; mean age, $56 \pm 13$ years; $22 \%$ with Marfan disease; 